\title{
Experimental research on semi-coke for blast furnace injection
}

\author{
Chun-chao Huang ${ }^{1,2} \cdot$ Xiao-jun Ning ${ }^{1,3} \cdot$ Guang-wei Wang ${ }^{1,2} \cdot$ Jian-liang Zhang ${ }^{1,2} \cdot$ Zheng-fu Peng $^{1,2} \cdot$ \\ Hai-peng Teng ${ }^{1,2}$
}

Received: 6 January 2020 / Revised: 28 June 2020 / Accepted: 29 June 2020 / Published online: 31 August 2020

(c) China Iron and Steel Research Institute Group 2020

\begin{abstract}
The combustion properties and grindability of Shenmu low-rank coal (SM) and its four different semi-cokes were studied by the self-designed equipment and Hardgrove method. The four semi-cokes were obtained under the pyrolysis temperature of 400, 500, 600 and $700^{\circ} \mathrm{C}$, named as SM-400, SM-500, SM-600 and SM-700, respectively. The analyses of nitrogen adsorption, Fourier-transform infrared spectroscopy (FTIR) spectra and Raman spectra were carried out to explain the change in combustion ratio and grindability. The result showed that the specific surface area of samples had an essential effect on the combustion ratio of SM-400 and SM-500. Meanwhile, the grindability depended on the strength of coal matrix, and the augment of pore amounts would increase the grindability. The functional groups and graphitization degree of the same sample were identical with the combustion ratio. With the pyrolysis upgrading temperature increasing, the combustion ratio of sample decreased, corresponding to the decrease in the benzene ring and the increase in graphitization degree. In addition, the thermogravimetric analysis was carried out, and the result was compared against what was shown in the data of combustion ratio. For pulverized coal injection, the combustion ratio was more intuitive and more accurate than combustibility.
\end{abstract}

Keywords Semi-coke $\cdot$ Combustion ratio $\cdot$ Functional group $\cdot$ Graphitization degree $\cdot$ Grindability

\section{Introduction}

Ironmaking is the basis of the metallurgical industry, and the blast furnace (BF) ironmaking is the primary supplier in the field of iron and steel manufacturing. Statistically, the total output of the crude steel was 443.0 million tonnes in the first 3 months of 2020 of the world, about $6.0 \%$ decrease compared to the same time of 2019 [1,2]. The downward trend can be ascribed to the COVID-19 pandemic. Regardless of the change in steel capacity, most of the crude steel production, about $64 \%$, was produced by

Xiao-jun Ning

ningxj@ustb.edu.cn

Guang-wei Wang

wgw676@163.com

1 State Key Laboratory of Advanced Metallurgy, University of Science and Technology Beijing, Beijing 100083, China

2 School of Metallurgical and Ecological Engineering, University of Science and Technology Beijing, Beijing 100083, China

3 Guanzhuang Campus, University of Science and Technology Beijing, Beijing 100083, China the integrated routes, which were blast furnace and basic oxygen furnace (BF-BOF) process [3]. The rest process, such as smelting reduction or direct reduction, accounts for only $5 \%$ of the crude steel production. As for China, in March 2020, the yield of crude steel was 79.0 Mt, a decrease of $1.7 \%$ compared with that in March 2019 [1]. With COVID-19 under control, the crude steel production will pick up. Almost all ironmaking processes adopt BF in China, and its iron output accounts for $62.2 \%$ of the global pig iron production. As we all know, the high-quality coke is an absolutely necessarily essential means of BF process. However, the coking process raises the problems that the ecological environment is deteriorated. Pulverized coal injection (PCI) is able to replace more than $30 \%$ of the metallurgical coke [4]. In China, the high-quality anthracite is the primary raw material for PCI. Unfortunately, the recoverable anthracite reserves are $1.131 \times 10^{4}$ Mt, accounting for only $13 \%$ of the total recoverable reserves of China [5]. The process of PCI is now facing with the problems of the increasing shortage of anthracite resources and substantially lower profits of ironmaking. On the contrary, the reserves of low-rank coal in China are $4.088 \times 10^{4} \mathrm{Mt}$, about four times of the anthracite, and its 
price is just 0.2 times of that of the anthracite [6]. Despite the lower cost and vast reserves, low-rank coal has its own disadvantages, like high moisture content, low combustion efficiency and strong explosibility, which restrict the widespread injection of it [7]. Thus, pyrolysis upgrading process is a meaningful way to make full use of such fuels. Pyrolysis technology accelerates the process of coalification. Furthermore, the pyrolysis process can be used costeffectively for removing moisture and volatile matter [7]. These steps will have an influence on the physical and chemical structures of semi-coke. The Hardgrove grindability index (HGI) and combustibility of coal are essential parameters in the process of PCI. Therefore, these two factors should be concerned during the application of semi-coke.

The grindability of coal involves how to choose the power of coal mill, which also has an essential influence on energy consumption and production costs $[8,9]$. Thus, the HGI of semi-coke mentioned above is a crucial factor needed to be studied. Yang et al. [10] found that the grindability of semicoke obtained under $500{ }^{\circ} \mathrm{C}$ decreased sharply, which was due to the coal plasticity and the process of volatilization. Besides, some work has been done on the study of combustion characteristics of semi-coke. Most of the research studied on these characteristics focused on thermogravimetric analysis and kinetic analysis among different samples. Wu et al. [11] studied the combustion properties and dynamic characteristics of the semi-coke sample, and they argued that the suitable upgrading temperature for combustibility was $500{ }^{\circ} \mathrm{C}$. Hu et al. [12] used three methods (FWO, KAS and Starink) to obtain the combustion activation energy of three different types of semi-cokes (110.66, 104.35 and $104.34 \mathrm{~kJ} \mathrm{~mol}^{-1}$ ). According to the previous work, it can be seen that the dynamic characteristics of combustion had been studied in detail. However, these researches were exhaustive, not illustrative, and the on-site guidance work was shoddy. In contrast, the combustion ratio is more intuitive than combustibility [13]. New experimental equipment developed independently by Prof. Yang and Dr. Korthas is used to test the combustion ratio of pulverized coal [13-15]. On the basis of the equipment, named the New Experimental Equipment for Combustion of Pulverized Coal (NEECPC) in blast furnace, the combustion ratios of the five samples were analyzed.

In this paper, some influence factors, such as particle size and specific surface area, of the combustion ratio of the semi-coke were investigated. In order to do further research, the aspects of chemical structure and carbonaceous structure were studied by the method of Fourier-transform infrared spectroscopy (FTIR) and Raman spectroscopy, respectively. Finally, combining the data of the combustion ratio and the grindability, the best pyrolysis upgrading temperature was selected.

\section{Material and experimental methods}

\subsection{Material preparation}

The raw coal named as Shenmu (SM) is collected from Shaanxi province, China. For large amounts of moisture, the dry pretreatment, for $4 \mathrm{~h}$ at $105^{\circ} \mathrm{C}$ in a drying oven, should be done before the experiment to remove all the free water. Then, the raw coal was crushed using a tray-type gyratory crusher, and the obtained particle was ground to $0.6-5.0 \mathrm{~mm}$ in diameter for further pyrolysis experiments. The preparation of semi-cokes was conducted in a quartz tube furnace with $\mathrm{N}_{2}$ atmosphere. The pyrolysis temperature was set to $400,500,600$ and $700{ }^{\circ} \mathrm{C}$, respectively, with the same holding time $(60 \mathrm{~min})$ and heating rate $\left(10^{\circ} \mathrm{C} / \mathrm{min}\right)$. Under each experimental condition, $260 \mathrm{~g}$ semi-coke was prepared for further test, with $250 \mathrm{~g}$ for grindability test and $10 \mathrm{~g}$ for combustion ratio test. The samples were marked as SM, SM-400, SM-500, SM-600 and SM-700, respectively. Each sample was milled and screened to obtain two particle size ranges: $0.60-1.25 \mathrm{~mm}$ for grindability tests and less than $74 \mu \mathrm{m}$ for combustion tests. All samples used for further testing (FTIR, Raman and nitrogen adsorption) were less than $74 \mu \mathrm{m}$. On the basis of the requirements of Chinese standards GB-T212 and GB-T476, the proximate analysis and ultimate analysis were performed. The high heating values (HHVs) of different samples were tested with the oxygen bomb calorimeter. The proximate and ultimate analysis and the HHV value of samples are shown in Table 1. The content of alkali metal $(\mathrm{K}, \mathrm{Na})$ was measured by the inductively coupled plasma mass spectrometry (ICP-MS). The results are described in Fig. 1.

\subsection{Sample characterization}

\subsubsection{Microstructure test}

The grain size distribution was tested using a laser particle size analyzer with high precision (Mastersizer 3000). The characteristics of pore structures and surface appearance were obtained by nitrogen adsorption method and scanning electron microscopy (SEM), respectively.

\subsubsection{FTIR spectra}

The functional groups of samples were detected by FTIR in the region of $500-4000 \mathrm{~cm}^{-1}$. In order to meet the requirements of FTIR analysis, the $\mathrm{KBr}$ pellet method was used to prepare the sample. The ratio of pulverized coal to $\mathrm{KBr}$ was 1 to $200 \mathrm{mg}$, and the mixture was ground for $2 \mathrm{~min}$ with a ball mill and then transferred into a suitable mold of the 
Table 1 Proximate and ultimate analyses of samples

\begin{tabular}{|c|c|c|c|c|c|c|c|c|c|c|}
\hline \multirow[t]{2}{*}{ Sample } & \multicolumn{3}{|c|}{ Proximate analysis/wt.\% } & \multicolumn{5}{|c|}{ Ultimate analysis/wt.\% } & \multirow{2}{*}{$\begin{array}{l}\text { Atomic ratio of } \\
(\mathrm{H}+\mathrm{O}) \text { to } \mathrm{C}\end{array}$} & \multirow[t]{2}{*}{$\mathrm{HHV} /\left(\mathrm{J} \mathrm{g}^{-1}\right)$} \\
\hline & $\mathrm{FC}_{\mathrm{d}}^{\mathrm{a}}$ & $\mathrm{A}_{\mathrm{d}}$ & $\mathrm{V}_{\mathrm{d}}$ & $\mathrm{C}_{\mathrm{d}}$ & $\mathrm{H}_{\mathrm{d}}$ & $\mathrm{O}_{\mathrm{d}}^{\mathrm{a}}$ & $\mathrm{N}_{\mathrm{d}}$ & $\mathrm{S}_{\mathrm{d}}$ & & \\
\hline SM & 60.36 & 3.39 & 36.25 & 73.74 & 5.05 & 16.60 & 0.83 & 0.39 & 0.99 & $29,898.27$ \\
\hline SM-400 & 62.83 & 3.27 & 33.90 & 76.31 & 4.83 & 14.22 & 0.99 & 0.38 & 0.90 & $30,557.54$ \\
\hline SM-500 & 67.16 & 4.29 & 28.55 & 81.57 & 4.30 & 8.32 & 1.10 & 0.42 & 0.71 & $31,093.24$ \\
\hline SM-600 & 75.08 & 6.52 & 18.40 & 82.46 & 2.95 & 6.58 & 1.12 & 0.37 & 0.49 & $32,238.31$ \\
\hline SM-700 & 83.39 & 5.60 & 11.01 & 85.97 & 2.01 & 4.98 & 1.08 & 0.36 & 0.32 & $32,458.82$ \\
\hline
\end{tabular}

${ }^{\mathrm{a} C a l c u l a t e d}$ by difference

FC Fixed carbon; A ash; V volatile matter; subscript d dry basis

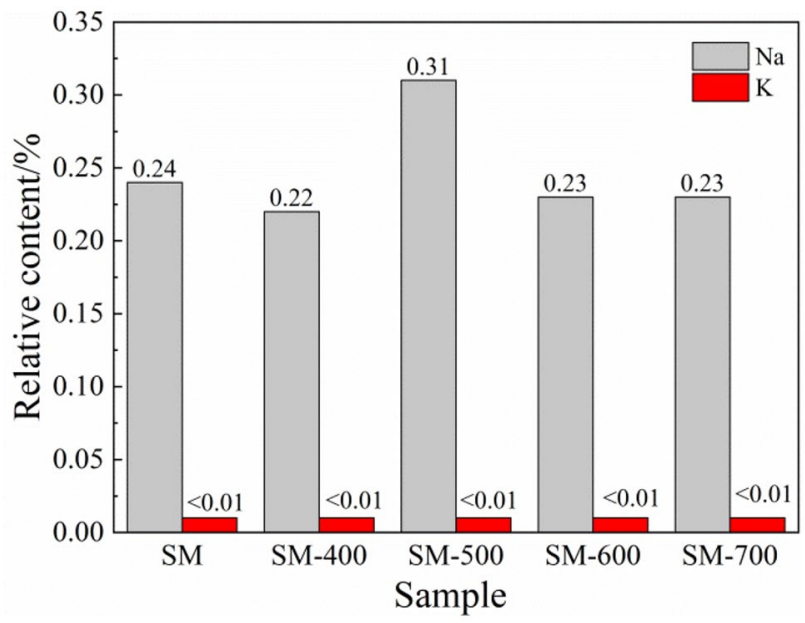

Fig. 1 Content of alkali metal infrared analyzer. The spectral resolution of analyzer was $4 \mathrm{~cm}^{-1}$; on the basis of this, each sample was scanned 32 times. The bands assignment of FTIR spectra is listed in Table 2 [16-19].

\subsubsection{Raman spectra}

By the method of Raman technology, the carbonaceous structure of the five samples was tested and analyzed in the region of $800-1800 \mathrm{~cm}^{-1}$. The analyzer used laser as a signal source, and its spectral resolution was $2 \mathrm{~cm}^{-1}$ with wavelength of $532 \mathrm{~nm}$. During the test, the spectrometer would select six regions for each sample. In addition, the fitted peaks of Raman spectra were studied with the method of Gaussian fitting. According to the studies [20-25], the bands assignment of Raman spectrum is presented in Table 3.

Table 2 Bands assignment of FTIR absorptive peaks $\left(500-4000 \mathrm{~cm}^{-1}\right)$

\begin{tabular}{|c|c|c|c|}
\hline \multirow[t]{2}{*}{ Band No. } & \multicolumn{2}{|c|}{ Wave number/cm ${ }^{-1}$} & \multirow[t]{2}{*}{ Vibration form and structure of absorption peak } \\
\hline & Position & Fluctuation range & \\
\hline 1 & 3633 & $3685-3600$ & Free $\mathrm{OH}$ groups \\
\hline 2 & 3525 & $3600-3500$ & $\mathrm{OH} \ldots \mathrm{OH}, \mathrm{OH} \ldots \mathrm{O}$ \\
\hline 3 & 3323 & $3350-3310$ & Stretching vibration of $\mathrm{NH}_{2}$ and $\mathrm{NH}$ \\
\hline 4 & 3050 & $3050-3030$ & Aromatic $\mathrm{CH}$ stretching vibration \\
\hline 5 & 2931 & $2975-2950$ & $\mathrm{CH}_{3}$ asymmetric stretching vibration in alkane ring or aliphatic \\
\hline 6 & 2860 & $2875-2860$ & $\mathrm{CH}_{2}$ asymmetric stretching vibration in alkane ring or aliphatic \\
\hline 7 & 1714 & $1715-1690$ & $\mathrm{COOH}$ stretching vibration in carboxyl acids \\
\hline 8 & 1599 & $1605-1595$ & $\mathrm{C}=\mathrm{C}$ stretching vibration in aromatic \\
\hline 9 & 1466 & $1480-1465$ & $\mathrm{CH}_{2}$ asymmetric deformation vibration in alkane ring or aliphatic \\
\hline 10 & 1301 & $1338-1260$ & Ar-O-C stretching vibration \\
\hline 11 & 1193 & $1160-1120$ & $\mathrm{C}-\mathrm{O}-\mathrm{C}$ stretching vibration \\
\hline 12 & 1033 & $1060-1020$ & $\mathrm{Si}-\mathrm{O}-\mathrm{Si}$ or $\mathrm{Si}-\mathrm{O}-\mathrm{C}$ stretching vibration \\
\hline 13 & 879 & $900-850$ & $\mathrm{CH}$ out-of-plane deformation vibration in benzene ring in which an $\mathrm{H}$ atom was substituted \\
\hline 14 & 818 & $825-800$ & $\begin{array}{l}\mathrm{CH} \text { out-of-plane deformation vibration in benzene ring in which three adjacent } \mathrm{H} \text { atoms were substi- } \\
\text { tuted }\end{array}$ \\
\hline 15 & 752 & $770-740$ & $\mathrm{H}$ out-of-plane deformation vibration in benzene ring in which five adjacent $\mathrm{H}$ atoms were substituted \\
\hline
\end{tabular}

Ar Aromatic group 
Table 3 Bands assignment of Raman spectra $\left(1000-1800 \mathrm{~cm}^{-1}\right)$

\begin{tabular}{llll}
\hline Band No. & Band name & Band position $/ \mathrm{cm}^{-1}$ & Vibration form and structure \\
\hline 1 & $\mathrm{D}_{1}$ & $1340-1358$ & Carbon edge atoms; impurity atoms and $s p^{2}$ carbon atoms (plane vibration) \\
2 & $\mathrm{D}_{2}$ & $1600-1620$ & Surface of graphite layer $\left(E_{2 \mathrm{~g}}\right.$ vibration) \\
3 & $\mathrm{D}_{3}$ & $1500-1550$ & Vibration of amorphous $s p^{2}$ hybridization carbon atoms \\
4 & $\mathrm{D}_{4}$ & $1180-1200$ & Lattice $s p^{2}-s p^{3}$ hybrid carbon atom; $\mathrm{C}-\mathrm{C}$ and $\mathrm{C}=\mathrm{C}$ in olefin (stretching vibration) \\
5 & $\mathrm{G}$ & $1590-1610$ & Aromatic ring quadrant breathing; alkene $\mathrm{C}=\mathrm{C}$ \\
6 & $\mathrm{~S}_{1}$ & $\sim 1269$ & Aryl-alkyl ether; para-aromatics \\
7 & $\mathrm{~S}_{2}$ & $\sim 1060$ & C-H on aromatic rings; benzene (ortho-disubstituted) ring \\
\hline
\end{tabular}

\subsubsection{Combustion ratio}

The combustion ratio of five samples was tested by NEECPC mentioned above. The theoretical basis and working conditions of this equipment have been introduced in detail in our previous work [13]. The combustion ratio is defined as the ratio of the burned mass of coal to the total mass before combustion. The gasses generated during the combustion process are $\mathrm{CO}_{2}$ and $\mathrm{CO}$. Since the burned mass of coal is not directly available, the device converts the burned mass of solid coal into the molar masses of $\mathrm{CO}_{2}$ and $\mathrm{CO}$. It is assumed that the total molar mass of carbon of coal sample is $n$, and the combustion process produces $n_{1} \mathrm{~mol}$ of $\mathrm{CO}$ and $n_{2}$ mol of $\mathrm{CO}_{2}$. Hence, the definition of combustion ratio is:

$\eta=\frac{n_{1}+n_{2}}{n}$

where $\eta$ is the combustion ratio of coal sample.

Under the control of the program, the temperature of hot air was maintained at $1200{ }^{\circ} \mathrm{C}$. The pulverized coal was blown into a furnace at $1500{ }^{\circ} \mathrm{C}$ after contacted with the hot air. The maximum speed of hot air was able to reach $235 \mathrm{~m} / \mathrm{s}$, and the maximum speed of the coal powder after acceleration was about $35 \mathrm{~m} / \mathrm{s}$. Therefore, the conditions of this device were very similar to those of the real BF. Each sample mass was $(0.100 \pm 0.001) \mathrm{g}$, weighed with an analytical balance. The combustion process of pulverized coal in the BF is incredibly complicated. On the basis of simulating the conditions as accurately as possible, the combustion ratio measured by NEECPC is an approximation, which is similar to combustibility, but more intuitive.

\subsubsection{Grindability test}

According to Chinese standard GB2565-2014, the grindability index of coal was measured with Hardgrove method. The device used was FYHM-60, a standard Hardgrove apparatus according to Chinese standard GB/T2565-1998. The preparation process for sample was done according to Chinese standard GB474. Owing to the change in microstructure during the pyrolysis process, keeping the same mass of each sample was crucial to preserve the same bed level during the ball-milling treatment. Specifically, each sample (50 g) was ground in the mill for $60 \mathrm{~s}$.

\section{Experimental results and discussion}

\subsection{Physical and chemical characteristics}

The physical and chemical characteristics of the five samples are revealed via the data of proximate and ultimate analyses, grain size distribution, SEM images, pore structures, FTIR spectra and Raman spectra. It can be found from Table 1 that the content of volatiles reveals a decreasing trend from SM to SM-700, while the content of fixed carbon or ash shows an opposite characteristics. What is more, the content of volatiles corresponds to the value of $(\mathrm{H}+\mathrm{O}) / \mathrm{C}$, which directly relates to the functional groups. Meanwhile, the high heating value of the sample increases from 29,898.27 to $32,458.82 \mathrm{~J} / \mathrm{g}$. The pyrolysis process is effective in removing volatiles; especially at $600{ }^{\circ} \mathrm{C}$, the rate of devolatilization is relatively higher. The sulfur content of semi-coke in this experiment is less than $0.42 \%$, which meets the requirements for sulfur content $(<0.5 \%)$ for high PCI rate $(180-210 \mathrm{~kg} / \mathrm{t})$ [26].

Although the content of alkalis in coal is very small, it is found that the alkalis not only possess good catalytic action but also can be used as fixing-sulfur sorbent [21]. Therefore, it is necessary to analyze the alkalis content in coal powder. The content of alkali metal of sample is shown in Fig. 1. It can be seen that the content of sodium in SM-500 is higher than that in others, but there is no evident relationship between the sodium content and the upgrading pyrolysis temperature. Due to the limitation in precision of the equipment, the potassium content is just given a rough range $(<0.01 \%)$. The results of particle size analysis are shown in Fig. 2, where D10, D50 and D90 are a value of particle size corresponding to $10 \%, 50 \%$ and $90 \%$ cumulative distribution 


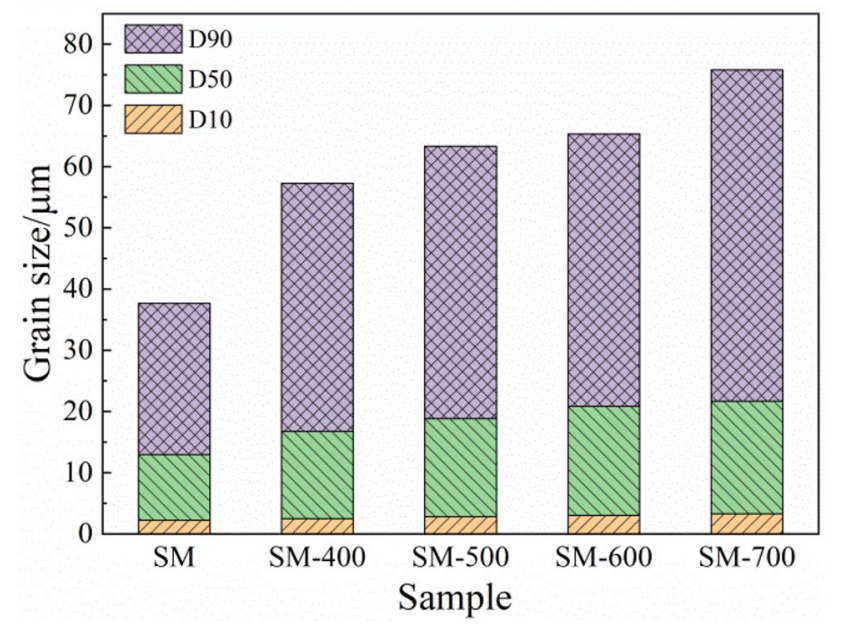

Fig. 2 Parameters of grain size distribution for combustion tests

of particle size, respectively. It can be seen that the D50 of semi-cokes is more than that of raw coal, and when the upgrading pyrolysis temperature increases, the particle size of sample becomes larger.

The surface morphology of the five samples is obtained by SEM, which is shown in Fig. 3. It can be seen that the surface of SM is uneven and irregular, with no visible pore. With an increase in the pyrolysis temperature, the amounts of pore on the surface gradually increase. However, the SEM image cannot be used for quantitative analysis of the pore structure of semi-coke. Thus, the changes in surface morphology of samples are studied by the method of nitrogen adsorption, as shown in Table 4, where $S_{\mathrm{t}}, V_{\mathrm{t}}$ and $D_{\mathrm{a}}$ represent the total surface area, the total pore volume and the average pore diameter, respectively. The changing trends of the parameters are shown in Fig. 4. It can be seen that $S_{\mathrm{t}}$ and $V_{\mathrm{t}}$ gradually increase with the increase in pyrolysis temperature; especially at $700{ }^{\circ} \mathrm{C}$, the two parameters increase
Table 4 Pore structure parameters of samples

\begin{tabular}{lccc}
\hline Sample & $S_{\mathrm{t}} /\left(\mathrm{m}^{2} \mathrm{~g}^{-1}\right)$ & $V_{\mathrm{t}} /\left(\mathrm{cm}^{3} \mathrm{~g}^{-1}\right)$ & $D_{\mathrm{a}} / \mathrm{nm}$ \\
\hline SM & 0.50 & $1.97 \times 10^{-3}$ & 16.51 \\
SM-400 & 0.99 & $3.43 \times 10^{-3}$ & 15.22 \\
SM-500 & 0.68 & $2.91 \times 10^{-3}$ & 12.16 \\
SM-600 & 2.33 & $4.56 \times 10^{-3}$ & 8.09 \\
SM-700 & 39.76 & $30.00 \times 10^{-3}$ & 3.32 \\
\hline
\end{tabular}

dramatically. It is worth mentioning that because of the tar formation or the coal plasticity [27], SM-500 has a slight decrease in $V_{\mathrm{t}}$ value. Actually, the larger specific surface area and pore volume mean that the sample has a stronger ability to adsorb the reacting gas and, additionally, mean higher reactivity.

The Raman spectra of five samples, including one raw coal and four semi-cokes, are shown in Fig. 5. According to the bands assignment mentioned in Table 3, the fitting curves are obtained via PeakFit software. It can be seen that the matching effect between fitting data and experiment data is preferable. There are two distinct peaks in Raman spectra at a wave number of around 1600 and $1350 \mathrm{~cm}^{-1}$, which are due to the $\mathrm{G}$ band and $\mathrm{D}$ band, respectively $[21,28]$. In fact, the relation between the intensity of the $\mathrm{G}$ band and the degree of graphitization is positive [29]. Sheng [30] held the idea that the ordering degree of coal sample could be measured by the values of $A_{\mathrm{D} 3+\mathrm{D} 4} / A_{\mathrm{G}}$ and $A_{\mathrm{G}} / A_{\mathrm{All}}$, where $A_{i}$ is the area corresponding to band $i$. It was also found in previous analysis that there was positive correlation (negative correlation) between the ordering degree of coal and the values of $A_{\mathrm{G}} / A_{\mathrm{All}}$ (the values of $A_{\mathrm{D} 3+\mathrm{D} 4} / A_{\mathrm{G}}$ ) [31]. These Raman spectra parameters of the five samples are listed in Table 5. As the pyrolysis temperature increases, the values of $A_{\mathrm{D} 3+\mathrm{D} 4} / A_{\mathrm{G}}$ decrease gradually, which is opposite to the variation trend of $A_{\mathrm{G}} / A_{\mathrm{All}}$. The result indicates that the ordering degree of
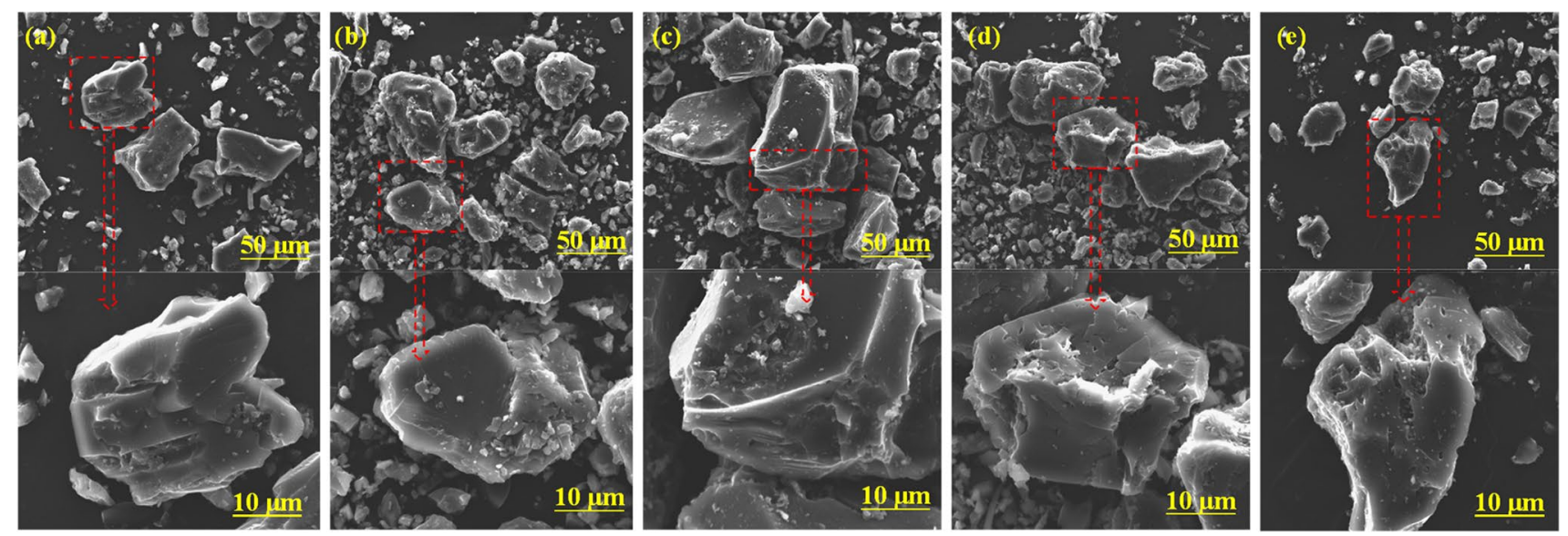

Fig. 3 SEM photographs of various coal particles. a SM; b SM-400; c SM-500; d SM-600; e SM-700 


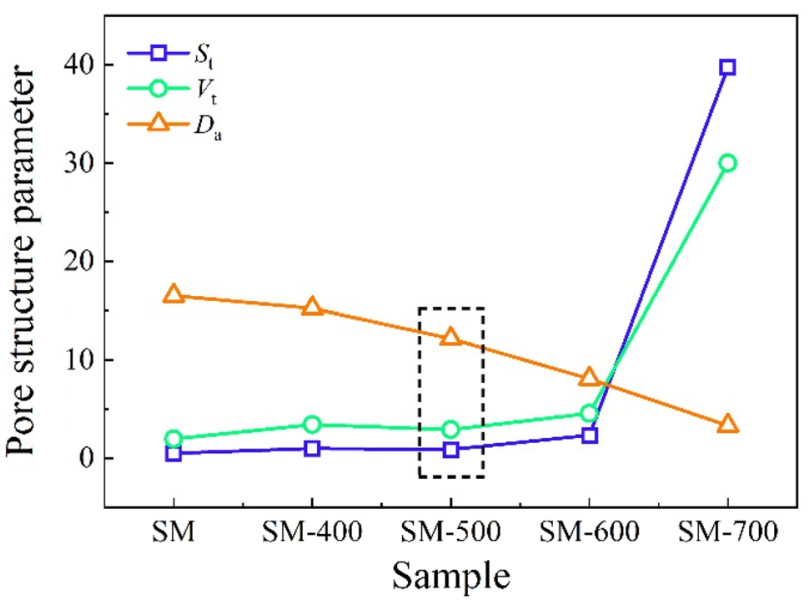

Fig. 4 Pore structure parameter line graph

the samples has been improved via the upgrading process, and the degree is closely related to the change in pyrolysis temperature. It is well known that the reactivity of coal will get worse, while the ordering degree increases. Therefore, it might mean that the reactivity of SM is higher than that of semi-coke, and the reactivity of semi-coke decreases gradually as the pyrolysis upgrading temperature changes from 400 to $700{ }^{\circ} \mathrm{C}$.

The functional groups of the five samples are tested by FTIR spectra at the wave number of $500-4000 \mathrm{~cm}^{-1}$. According to the bands assignment shown in Table 2, the results are depicted in Fig. 6. It can be seen that the shapes of absorption peak of each sample are similar, meaning that the raw coal and semi-cokes have the same type of functional groups. By comparison of previous literature [32], the functional groups of coal can be divided into four categories, namely hydrogen bonding $\left(3000-3600 \mathrm{~cm}^{-1}\right)$, fat chain (2800-3000 $\mathrm{cm}^{-1}$ ), oxygen-containing functional groups $\left(1000-1800 \mathrm{~cm}^{-1}\right)$ and aromatic structure $\left(700-900 \mathrm{~cm}^{-1}\right)$, respectively.

The peak intensity of FTIR spectra is positively correlated with the concentration of corresponding functional groups [33]. For the region of $3000-3600 \mathrm{~cm}^{-1}$, there are three obvious peaks at 3633,3525 and $3323 \mathrm{~cm}^{-1}$, which are due to $-\mathrm{OH}$ stretching vibration in alcohols and stretching vibration of $\mathrm{NH}_{2}$ and $\mathrm{NH}$. The peaks at 2931 and $2860 \mathrm{~cm}^{-1}$ are assigned to the asymmetric stretching vibration of $\mathrm{CH}_{3}$ and $\mathrm{CH}_{2}$ in alkane ring or aliphatic. There are six bands at 1714 , $1599,1466,1301,1193$ and $1033 \mathrm{~cm}^{-1}$, which are assigned to the vibration of $\mathrm{COOH}, \mathrm{C}=\mathrm{C}, \mathrm{CH}_{2}, \mathrm{Ar}-\mathrm{O}-\mathrm{C}, \mathrm{C}-\mathrm{O}-\mathrm{C}$ and $\mathrm{Si}-\mathrm{O}-\mathrm{Si}(\mathrm{C})$. The amount of oxygen-containing functional groups with high reactivity is relatively more in coal [27]. Besides, the oxygen-containing functional groups may have an effect on the combustion of semi-coke. The intensity of the three types of groups which was just discussed has a significant decrease due to the pyrolysis upgrading process, especially related to the increasing amplitude in pyrolysis temperature. The peaks at 879,818 and $752 \mathrm{~cm}^{-1}$ can all be attributed to the different $\mathrm{H}$ atom vibrations in the benzene ring. From SM to SM-600, there is a stable intensity growth of the peaks at the region of 700-900 $\mathrm{cm}^{-1}$, accompanied by occasional fluctuations. However, the peaks of SM-700 are lower than those of SM-600, which may be attributed to the twice polycondensation reaction. More specifically, the concentration of benzene ring can be used to assess the effect of pyrolysis upgrading to some extent [18].

The results shown by Raman spectra and FTIR spectra have the same effect in the structural characteristics. The higher the degree of graphitization of coal sample is, the less content the reactive functional groups with high activity will be, while it is opposite in terms of the poor activity groups, such as benzene ring.

\subsection{Correlation between structural characteristics and combustion ratio}

The combustion ratio of the samples is obtained by NEECPC, and the data are shown in Table 6. The analysis of combustion ratio shows that the combustion ability of SM sample is better than that of semi-coke sample. As the pyrolysis temperature increases from 400 to $700{ }^{\circ} \mathrm{C}$, the flammability of semi-coke presents a descending trend. This changing trend can be directly related to the structure. Specifically, the proximate analysis indicates that the pyrolysis process can effectively remove the volatile matter and increase the content of fixed carbon, which is closely related to the value of $(\mathrm{H}+\mathrm{O}) / \mathrm{C}$. The combustion process of coal powder is almost instantaneous, which is different from the thermogravimetric analysis. Therefore, the volatile matter has an effect on combustion ratio to some extent. As for alkali metal analysis, little difference between the combustion ratio of SM-400 and SM-500 can be observed, which may mean that the catalysis of sodium is the primary reason. Through the microstructure analysis, including grain size analysis, SEM image and nitrogen adsorption, the burning capacity of samples can be explained. Most of the SM samples are in the form of amorphous carbon, while semi-coke shows a tendency to graphitize. Quantitative analysis for carbon structure with Raman spectra reveals the changing tendency of graphitization degree. On the basis of that, it can be seen that the high graphitization degree is corresponding to $\mathrm{C}=\mathrm{C}$ (with high bond energy), and $\mathrm{C}=\mathrm{C}$ in carbon rings is difficult to devolatilize. Therefore, the combustion ratio of SM is better than that of semi-cokes, and the combustion ratio of semi-cokes decreases when the upgrading temperature increases. In addition, for the combustion ratio, there is little difference between SM-500 and SM-400, although the volatile content of SM-500 is lower than that of SM-400. 

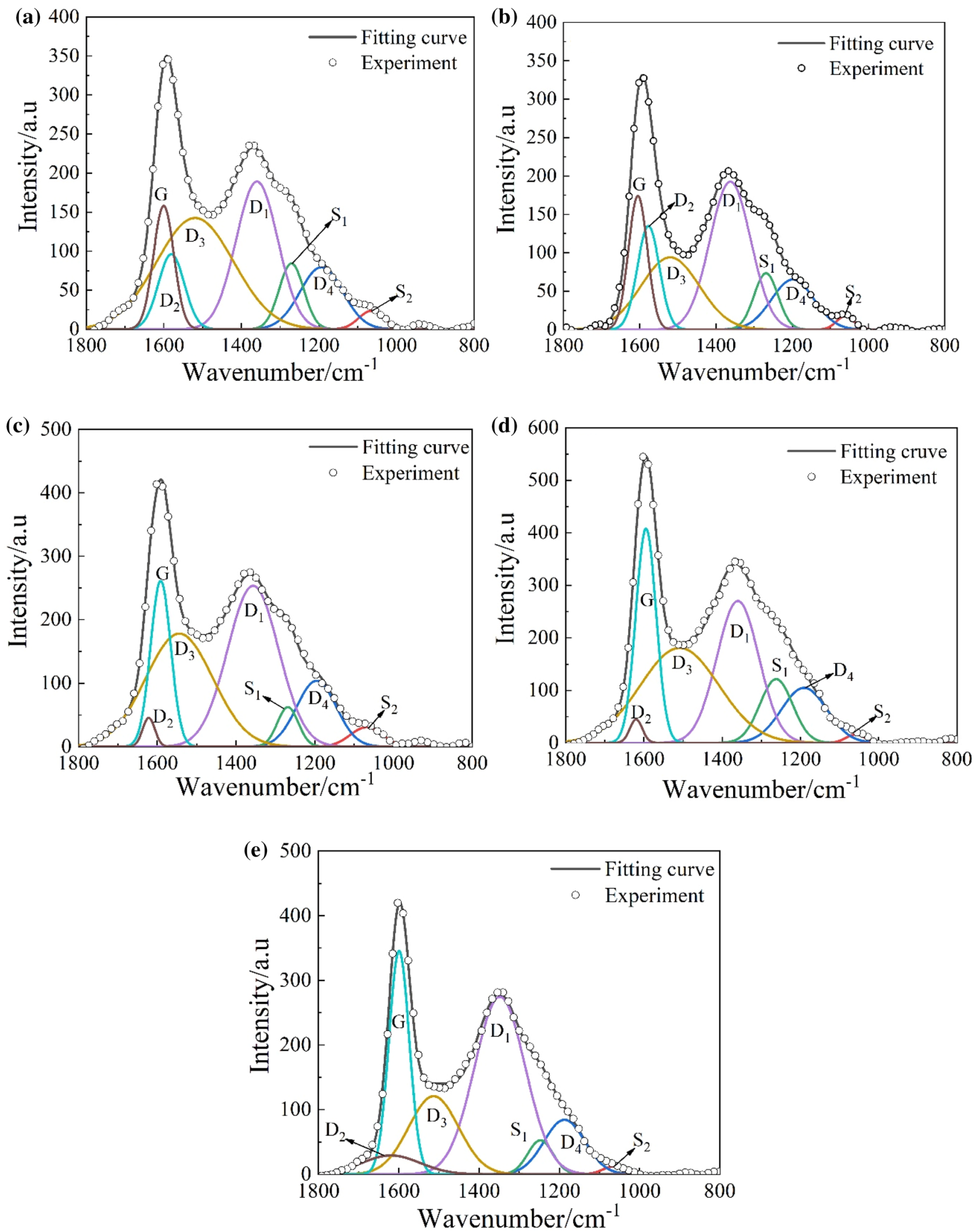

Fig. 5 Raman spectra of five samples. a SM; b SM-400; c SM-500; d SM-600; e SM-700 
Table 5 Raman spectra parameters of five samples

\begin{tabular}{|c|c|c|c|c|c|c|c|c|c|}
\hline Sample & $A_{\mathrm{D} 1}$ & $A_{\mathrm{D} 2}$ & $A_{\mathrm{D} 3}$ & $A_{\mathrm{D} 4}$ & $A_{\mathrm{G}}$ & $A_{\mathrm{D} 3+\mathrm{D} 4} / A_{\mathrm{G}}$ & $A_{\mathrm{G}} / A_{\mathrm{All}}$ & $A_{\mathrm{S} 1}$ & $A_{\mathrm{S} 2}$ \\
\hline SM & $25,483.5$ & $10,409.7$ & $35,461.9$ & $10,948.5$ & 8077.0 & 5.746 & 0.082 & 6708.1 & 1916.0 \\
\hline SM-400 & $25,861.1$ & $10,764.5$ & $18,020.4$ & 9090.5 & 9722.8 & 2.788 & 0.121 & 5773.2 & 990.4 \\
\hline SM-500 & $41,112.3$ & 1772.4 & $38,143.9$ & $13,088.3$ & $16,825.6$ & 3.045 & 0.142 & 4151.5 & 3158.4 \\
\hline SM-600 & $36,321.0$ & 1795.3 & $45,580.5$ & $15,247.3$ & $26,574.5$ & 2.289 & 0.191 & $12,710.5$ & 982.7 \\
\hline SM-700 & $43,400.7$ & 5282.8 & $18,752.6$ & $10,720.2$ & $21,877.6$ & 1.347 & 0.208 & 4137.9 & 811.2 \\
\hline
\end{tabular}

Table 6 Combustion ratio of five samples (\%)

\begin{tabular}{lll}
\hline Sample & Experiment data & Average value \\
\hline SM & $81.63,84.00,83.44,83.30$ & 83.09 \\
SM-400 & $75.56,77.09,78.60,76.77$ & 77.01 \\
SM-500 & $72.24,74.78,72.39,73.11$ & 73.13 \\
SM-600 & $62.46,64.95,66.10,63.61$ & 64.28 \\
SM-700 & $59.57,60.13,57.94,61.92$ & 59.89 \\
\hline
\end{tabular}

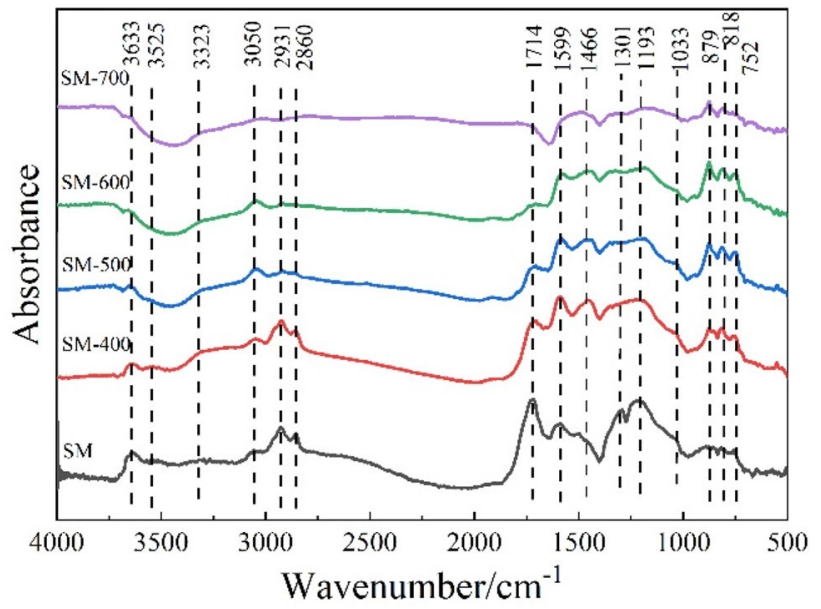

Fig. 6 FTIR spectra of raw coal and four semi-cokes

This phenomenon may be due to the small difference among the parameters of pore structure, especially the specific surface area. Therefore, the combustion ratio may be influenced by not only the volatiles but also the specific surface area.

For FTIR analysis, it can be seen that the pyrolysis process can remove most of the hydrogen bonds and fat structures, which can be seen from the intensity of the corresponding peaks. Thus, the remaining oxygen-containing functional groups will account for a large part. According to Xiang et al. [33], the oxygen-containing functional groups would decompose preferentially at $200-450{ }^{\circ} \mathrm{C}$. The high intensity of oxygen-containing functional groups plays an essential role in the high combustion ratio of SM and SM-400. Meanwhile, the increase in intensity at the region of $700-900 \mathrm{~cm}^{-1}$ indicates that the $\mathrm{C}-\mathrm{H}$ vibration in the benzene ring has been enhanced, corresponding to less mass of the active functional groups. The low combustion ratio of SM-700 is the result of the joint action of the two factors: a small amount of the oxygen-containing functional groups and lots of the benzene rings.

\subsection{Comparison of combustion ratio and combustibility}

In order to compare the combustion ratio with the combustibility, a thermogravimetric experiment has been carried out. The experimental method and device have been introduced in detail in our previous work [29, 34]. Five parameters, namely $T_{\mathrm{i}}$ (temperature at which the mass loss reaches $5 \%$ of the total mass), $T_{\mathrm{f}}$ (temperature at which the mass loss reaches $95 \%$ of the total mass $),(\mathrm{d} x / \mathrm{d} t)_{\max },(\mathrm{d} x / \mathrm{d} t)_{\text {mean }}$ and $S$, are defined as the initial temperature of mass loss, the end temperature of mass loss, maximum burning rate, mean burning rate and comprehensive combustion index, respectively.

Equation (2) shows the relationship among the five parameters. The $S$ value can provide a more comprehensive analysis in the combustion process. The higher the $S$ value is, the better combustibility the coal has [35]:

$S=\frac{(\mathrm{d} x / \mathrm{d} t)_{\text {mean }} \cdot(\mathrm{d} x / \mathrm{d} t)_{\max }}{T_{\mathrm{i}}^{2} \cdot T_{\mathrm{f}}}$

The thermogravimetric analysis (TGA) is carried out at the heating rate of $20{ }^{\circ} \mathrm{C} / \mathrm{min}$, and the results are shown in Fig. 7. It can be seen that the parameters $T_{\mathrm{i}}$ and $T_{\mathrm{f}}$ show an increase in the value with the increase in pyrolysis upgrading temperature, while the $S$ value shows an opposite character. As for SM-500, the relatively high level of $(\mathrm{d} x / \mathrm{d} t)_{\max }$ in Fig. 7b seems consistent with the changing trend of combustion ratio, which can also be due to the high porosity and high content of the alkali metal oxides. The $S$ value of SM-500 is very close to those of SM and SM-400, which means that the combustibility among them is slightly different. Although the result of combustibility presents a similar trend with the combustion ratio, as shown in Fig. 8, there is variation 

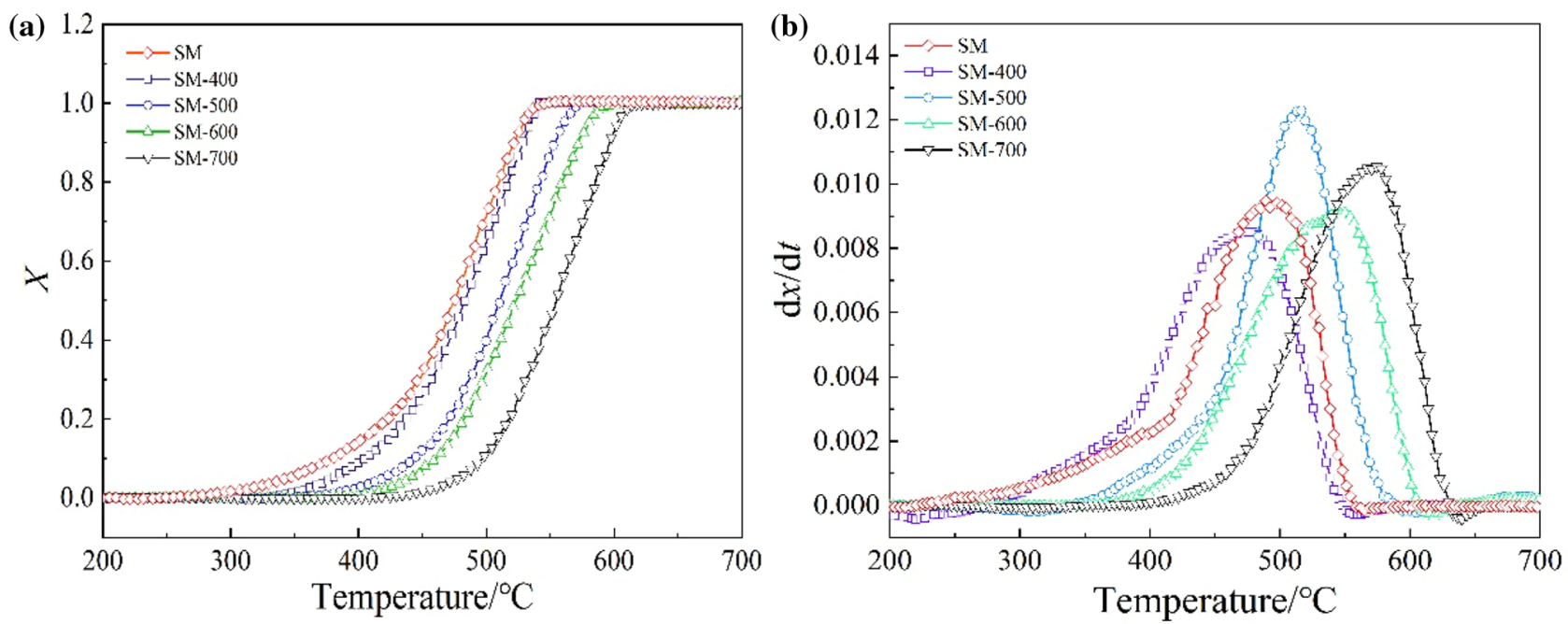

Fig. 7 Experimental conversion $(X)$ and conversion rate $(\mathrm{d} x / \mathrm{d} t)$ curves of five samples a Thermogravimetric curve; b differential thermogravimetric curve

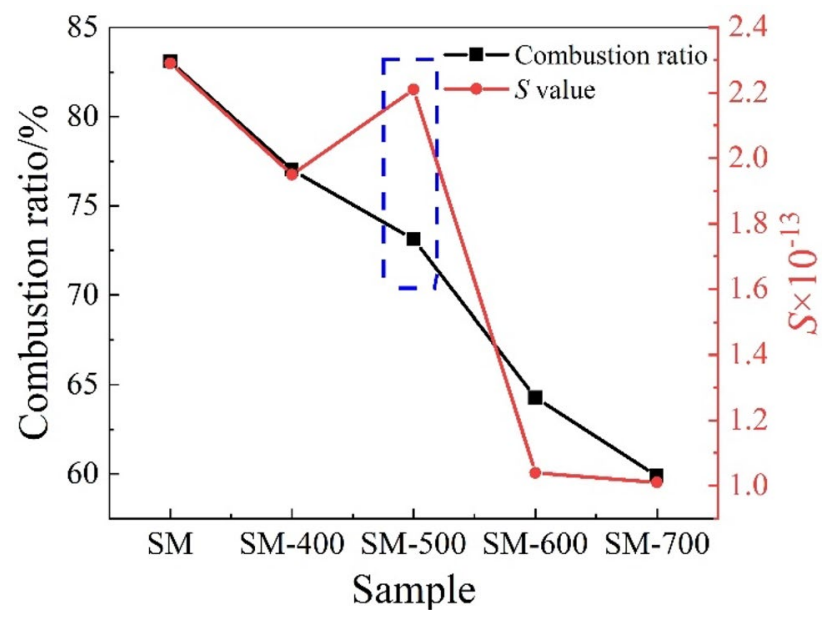

Fig. 8 Comparison of combustion ratio and comprehensive combustion index

between the two values in SM-500. Unlike the NEECPC equipment, which can simulate the real environment of $\mathrm{BF}$ tuyere with the heating rate of about $10^{6}{ }^{\circ} \mathrm{C} / \mathrm{s}[36$, 37], the heating rate of TGA is only $20{ }^{\circ} \mathrm{C} / \mathrm{min}$ of this experiment. During the slow reaction of TGA, the pore structure of the sample will change further, and the effect time of the alkali metals will be longer. These are the reasons for the difference in combustion ratio and combustibility. Therefore, the $S$ value is not a substitute for the combustion ratio because of its abstraction and complication (Table 7).

\subsection{Correlation between structural characteristics and grindability}

The grindability index of the five samples is described in Fig. 9. It can be seen that the grindability of raw coal is the minimum with the number of just 40.4 . There is a clear inflection point at $600{ }^{\circ} \mathrm{C}$ with the value of 52.4 , and before it, the HGI value shows a tendency to increase with the increase in upgrading temperature. This change can be attributed to the rapid removal of volatile matter, which destroys the internal pore structure of the semi-coke. The parameters of pore structure are shown in Table 4 and Fig. 4. This stated a fact that has been confirmed by Yang et al. [10] that pore is generated as strength of coal matrix decreases. The result of the polycondensation reaction between 600 and $700{ }^{\circ} \mathrm{C}$ improved the strength of semi-coke matrix, although

Table 7 Combustion parameters of different samples

\begin{tabular}{llllll}
\hline Sample & $T_{\mathrm{i}}$ & $T_{\mathrm{f}}$ & $(\mathrm{d} x / \mathrm{d} t)_{\max } / \mathrm{min}^{-1}$ & $(\mathrm{~d} x / \mathrm{d} t)_{\operatorname{mean}} / \mathrm{min}^{-1}$ & $S$ \\
\hline SM & 344.89 & 529.05 & 0.00851 & 0.00169 & $2.29 \times 10^{-13}$ \\
SM-400 & 379.01 & 535.05 & 0.00948 & 0.00158 & $1.95 \times 10^{-13}$ \\
SM-500 & 419.46 & 560.59 & 0.01231 & 0.00177 & $2.21 \times 10^{-13}$ \\
SM-600 & 523.54 & 580.22 & 0.00916 & 0.00180 & $1.04 \times 10^{-13}$ \\
SM-700 & 555.40 & 602.74 & 0.01060 & 0.00177 & $1.01 \times 10^{-13}$ \\
\hline
\end{tabular}




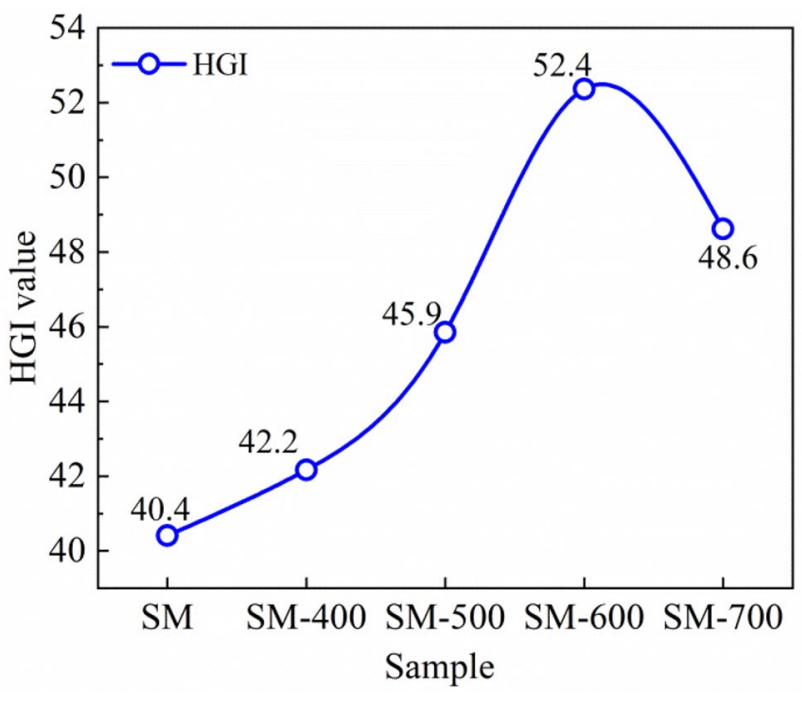

Fig. 9 Grindability of different samples

the pore structure has been greatly developed. Furthermore, the FTIR analysis can also be invoked to explain the change in gradability between 600 and $700{ }^{\circ} \mathrm{C}$. As the pyrolysis temperature changes from 400 to $600{ }^{\circ} \mathrm{C}$, the peak intensity of benzene ring (700-900 $\mathrm{cm}^{-1}$ ) has increased, but at $700{ }^{\circ} \mathrm{C}$, its intensity has shown a significant decline in benzene ring. This phenomenon can be due to the polycondensation process of the benzene ring with high polymerization degree. The value of $A_{\mathrm{D} 3+\mathrm{D} 4} / A_{\mathrm{G}}$ or $A_{\mathrm{G}} / A_{\mathrm{All}}$ is also corresponding to the FTIR analysis. It is worth noting that the value of $A_{\mathrm{G}} / A_{\mathrm{All}}$ at $700{ }^{\circ} \mathrm{C}$ is 0.208 , increased by about $8.9 \%$ as compared with that of SM-600, and its amplitude of increase is the largest. The increase in graphitization degree can reveal not only the combustion ratio, but also the mechanical strength of sample and the reduction in grindability.

\section{Conclusion}

The carbonaceous structure and functional groups for combustion ratio and grindability of different semi-cokes were studied. The combustion ratio of semi-coke decreased, while the pyrolysis temperature increased, corresponding to the higher degree of graphitization (Raman analysis) and higher content of benzene ring (FTIR analysis). The increase in amounts of pore would reduce the strength of the coal matrix and increase the grindability. After the peak of HGI $\left(600^{\circ} \mathrm{C}\right)$, polycondensation happened in the semi-coke matrix, which caused the grindability of SM-700 to reduce. Considering each kind of situation, especially the combustion ratio and the grindability, SM-600 was comparatively better than that of other semi-cokes and raw coal.
Acknowledgements This work was supported by the Natural Science Foundation for Young Scientists of China (No. 51804026) and the Fundamental Research Funds for the Central Universities (FRF-AT-18-001).

\section{References}

[1] World Steel Association, March 2020 crude steel production: Brussels, Belgium, Word Steel Association press release, April 22 (2020).

[2] H. Suopajarvi, E. Pongracz, T. Fabritius, Renew. Sustain. Energy Rev. 25 (2013) 511-528.

[3] A. Babich, D. Senk, M. Fernandez, ISIJ Int. 50 (2010) 81-88.

[4] M.A. Díez, R. Alvarez, C. Barriocanal, Int. J. Coal Geol. 50 (2002) 389-412.

[5] S. Han, H. Chen, R.Y. Long, X.T. Cui, Resour. Conserv. Recycl. 129 (2018) 293-306.

[6] Z.H. Rao, Y.M. Zhao, C.L. Huang, C.L. Duan, J.F. He, Prog. Energy Combust. Sci. 46 (2015) 1-11.

[7] M. Karthikeyan, W. Zhonghua, A.S. Mujumdar, Drying Technol. 27 (2009) 403-415.

[8] J.X. Guo, L.L. Zhang, W.B. Dai, L.Y. Qi, R.F. Wei, D.Q. Cang, J. Iron Steel Res. Int. 26 (2019) 11-19.

[9] R.S. Xu, W. Wang, B.W. Dai, J. Iron Steel Res. Int. 25 (2018) 1213-1222.

[10] Y.M. Yang, J.Z. Liu, J. Wang, J. Cheng, Z.H. Wang, K.F. Cen, Energy Fuels 32 (2018) 1297-1308.

[11] H. Wu, C. Zou, J.Y. He, K. Wang, Z.W. Liu, S. Shi, Chin. J. Process Eng. 20 (2020) 449-457.

[12] Y.J. Hu, Z.Q. Wang, X.X. Cheng, C.Y. Ma, RSC Adv. 8 (2018) 22909-22916.

[13] Y.F. Chai, J.L. Zhang, Q.J. Shao, X.J. Ning, K.D. Wang, High Temp. Mater. Processes 38 (2019) 42-49.

[14] J.L. Zhang, D.H. Huang, X.D. Zhang, J. Chang, J. Univ. Sci. Technol. Beijing 31 (2009) 633-637.

[15] Z.F. Peng, J.L. Zhang, C.G. Bi, X.J. Ning, P.L. Tan, G.W. Wang, Iron and Steel 54 (2019) No. 12, 10-18.

[16] J. Ibarra, E. Munoz, R. Moliner, Org. Geochem. 24 (1996) $725-735$.

[17] E.L. Zodrow, M. Mastalerz, U. Werner-Zwanziger, J.A. D’Angelo, Int. J. Coal Geol. 82 (2010) 116-124.

[18] H.J. Song, G.R. Liu, J.Z. Zhang, J.H. Wu, Fuel Process. Technol. 156 (2017) 454-460.

[19] Q.Z. Li, B.Q. Lin, C.S. Zhao, W.F. Wu, Proceedings of the CSEE 31 (2011) No. 32, 46-52.

[20] A. Sadezky, H. Muckenhuber, H. Grothe, R. Niessner, U. Pöschl, Carbon 43 (2005) 1731-1742.

[21] G.W. Wang, J.L. Zhang, G.H. Zhang, X.J. Ning, X.Y. Li, Z.J. Liu, J. Guo, Energy 131 (2017) 27-40.

[22] S.P. Jones, C.C. Fain, D.D. Edie, Carbon 35 (1997) 1533-1543.

[23] T. Jawhari, A. Roid, J. Casado, Carbon 33 (1995) 1561-1565.

[24] K. Ishimaru, T. Hata, P. Bronsveld, T. Nishizawa, Y. Imamura, J. Wood Sci. 53 (2007) 442-450.

[25] K.J. Li, R. Khanna, J.L. Zhang, M. Barati, Z.J. Liu, T. Xu, T.J. Yang, V. Sahajwalla, Energy Fuels 29 (2015) 7178-7189.

[26] C.G. Bi, C.C. Huang, X.J. Ning, J.L. Zhang, G.W. Wang, Z.F. Peng, Iron and Steel 55 (2020) No. 6, 25-32.

[27] K.C. Xie, Coal structure and its reactivity, Science Press, Beijing, China, 2002.

[28] R. Rajarao, I. Mansuri, R. Dhunna, R. Khanna, V. Sahajwalla, J. Anal. Appl. Pyrolysis 105 (2014) 14-22.

[29] S.Y. Wu, S. Huang, L.Y. Ji, Y.Q. Wu, J.S. Gao, Fuel 122 (2014) $67-75$. 
[30] C.D. Sheng, Fuel 86 (2007) 2316-2324.

[31] X.C. Liu, B. Fang, Z.G. Zhao, R.L. Xie, Z. Lei, Q. Ling, P. Cui, J. Iron Steel Res. Int. 26 (2019) 1052-1060.

[32] H.I. Petersen, P. Rosenberg, H.P. Nytoft, Int. J. Coal Geol. 74 (2008) 93-113.

[33] J. Xiang, S. Hu, L.S. Sun, M.H. Xu, P.S. Li, S. Su, X.X Sun, J. Chem. Ind. Eng. (China) 57 (2006) 2180-2184.

[34] Q. Wang, J.L. Zhang, G.W. Wang, H.Y. Wang, M.M. Sun, Energy Fuels 32 (2018) 2145-2155.
[35] X.G. Li, Y. Lv, B.G. Ma, S.W. Jian, H.B. Tan, Bioresour. Technol. 102 (2011) 9783-9788.

[36] H.B. Jiang, J.L. Zhang, J.X. Fu, J. Chang, J. Li, J. Iron Steel Res. Int. 18 (2011) No. 3, 6-12.

[37] Q.H. Tang, X.L. Wang, C.L. Qi, Knowledge on blast furnace pulverized coal injection, 2nd Ed., Metallurgical Industry Press, Beijing, China, 2016. 